\title{
Comparison of ionospheric characteristic parameters obtained by GPS and ionosonde with IRI model over China
}

\author{
Cheng Wang \\ Collaborative Innovation Center for Geospatial Information Technology, No. 129 Luoyu Road, \\ Wuhan 430079, China. \\ GNSS Research Center, Wuhan University, No. 129 Luoyu Road, Wuhan 430079, China. \\ e-mail:ac@geodesy.cn
}

This paper presents a comparison of ionospheric characteristic parameters obtained by a GPS network and three ionosondes at Mohe $\left(122.4^{\circ} \mathrm{E}, 53.5^{\circ} \mathrm{N}\right.$, dip angle $\left.70.983^{\circ} \mathrm{N}\right)$, Zuolingzhen $\left(114.6^{\circ} \mathrm{E}, 30.5^{\circ} \mathrm{N}\right.$, dip angle $\left.46.350^{\circ} \mathrm{N}\right)$, and Fuke $\left(109.1^{\circ} \mathrm{E}, 19.5^{\circ} \mathrm{N}\right.$, dip angle $\left.27.083^{\circ} \mathrm{N}\right)$ located in China with an IRI model in the year 2011. Observed NmF2 and hmF2 values at the three stations are compared with IRI2007 and IRI2012 predictions, respectively. The results show that there are clear linear correlations between the observed values and the IRI model predicted values. The IRI model gives overestimations at the three stations mostly in 2011. For the NmF2 and hmF2 values, most of the results show that the IRI2012 predicted values are closer to the observed values compared with those of IRI2007. Additionally, the GPS TEC values derived from the Crustal Movement Observation Network of China (CMONOC) are compared with the IRI2012 predictions. From the results, it is evident that the IRI2012 model predictions follow the normal trend of diurnal variation of GPS measured TEC monthly means but do not reproduce the measured data well. The IRI2012 model overestimates electron density in the latter part of spring as well as the first half of autumn and winter and underestimates electron density in early spring and the latter part of autumn. Referring to GPS TEC, the precision of the IRI2012 model predicted TEC values is $~ 5$ TECU over China. It may also be noted that there are two discontinuities of IRI-TEC monthly means appearing in November and December of the year 2011. This brings a bias of $\sim 3$ TECU of TEC values between two adjacent months.

\section{Introduction}

The ionosphere is an important part of the Earth's upper atmosphere. It is ionized by solar radiation and influences radio propagation (Dungey 1955). Ionospheric sounding is significant for studying the ionosphere. Some characteristic parameters can be obtained by traditional equipment such as an ionosonde, sounding rocket and radar, as well as GPS (Huang and Reinisch 2001; Ma and Maruyama 2003; Sobral et al. 2003; Brunini et al. 2004; Lei et al. 2005; Mosert et al. 2007; Liu et al. 2009). To meet the needs of application in satellite positioning and the study of ionospheric physics, a few models of the ionosphere have been built, such as the Klobuchar model (Klobuchar 1987), the International Reference Ionosphere (IRI) model (Bilitza 2001; Bilitza and Reinisch 2008; Bilitza et al. 2011), and the NeQuick model (Dudeney 1978). These models are suited

Keywords. TEC; NmF2; hmF2; GPS; IRI model; IRI2012. 
for scientific analysis of the general trend of the ionosphere. Additionally, global ionosphere maps (GIM) have been generated for over a decade by the IGS Ionosphere Associate Analysis Centers (IAACs) (Hernández-Pajares et al. 2009).

The IRI model is an international project sponsored by the Committee on Space Research (COSPAR) and the International Union of Radio Science (URSI). The IRI model can provide monthly averages of the electron density, electron temperature, ion temperature, and ion composition (Bilitza 2001). Several improved editions of the IRI model have been released from the 1960s. The latest version of the model is IRI2012. The major update is that new neural network-based global models for the F2 peak parameters are developed and evaluated (Bilitza et al. 2011). Many authors have reported evaluations of the IRI model using some ionospheric characteristic parameters over many areas of the world during quiet or active space weather, such as IRI predicted $\mathrm{NmF} 2$ and hmF2 values (Adeniyi et al. 2003; Araujo-Pradere et al. 2003; Bilitza et al. 2004; Lee and Reinisch 2006; Oyeyemi et al. 2013; Wichaipanich et al. 2013; Ikubanni et al. 2014), and IRI predicted TEC (Bhuyan and Borah 2007; Adewale et al. 2011; Kenpankho et al. 2013; Okoh et al. 2013; Olwendo et al. 2013). They have shown the abilities and improvements of the IRI model to predict ionospheric parameters in recent years.

In this paper, we use data from three ionosondes from the Meridian Space Weather Monitoring Project and $\sim 260$ GPS receivers from the Crustal Movement Observation Network of China (CMONOC) in the year 2011. The ionospheric parameters, including $\mathrm{NmF} 2$ and hmF2, observed by ionosondes and GPS TEC derived from satellite measurements are compared with IRI predictions. In calculations of IRI predictions, we use URSI coefficients for the foF2 values and turn on STORM model as well as E-storm model.

\section{Data and methodology}

The ionosonde data used in this work are collected at three ionosonde stations in China, namely Mohe $\left(122.4^{\circ} \mathrm{E}, 53.5^{\circ} \mathrm{N}\right.$, dip angle $70.983^{\circ} \mathrm{N}$, hereafter referred to as $\mathrm{MH})$, Zuolingzhen $\left(114.6^{\circ} \mathrm{E}, 30.5^{\circ} \mathrm{N}\right.$, dip angle $46.350^{\circ} \mathrm{N}$, hereafter referred to as ZLZ), and Fuke $\left(109.1^{\circ} \mathrm{E}, 19.5^{\circ} \mathrm{N}\right.$, dip angle $27.083^{\circ} \mathrm{N}$, hereafter referred to as FK). The GPS TEC values estimated by using GPS measurements with 30-sec intervals from CMONOC. The geographical locations of all stations including the three ionosondes and GPS receivers used in this study are shown in figure 1. The three black triangles depict the locations of the three ionosondes. The red points show all GPS receivers used in this work, and there are also 999 blue points selected for comparison of GPS TEC with IRI-TEC prediction over China. In addition, the grey lines are the ionospheric pierce points (IPP) during $24 \mathrm{hrs}$. The temporal distribution of available data at the three ionosondes is shown in figure 2 . The blank portion indicates that there is no data available at the three ionosondes, and $\mathrm{NmF} 2$ and hmF2 observed by each station are depicted in figure 3 . The black points in figure 3 show the available values of $\mathrm{NmF} 2$ and hmF2 observed by the three ionosondes respectively. The red lines through the black points are the 9 th order polynomial fit of these values respectively.

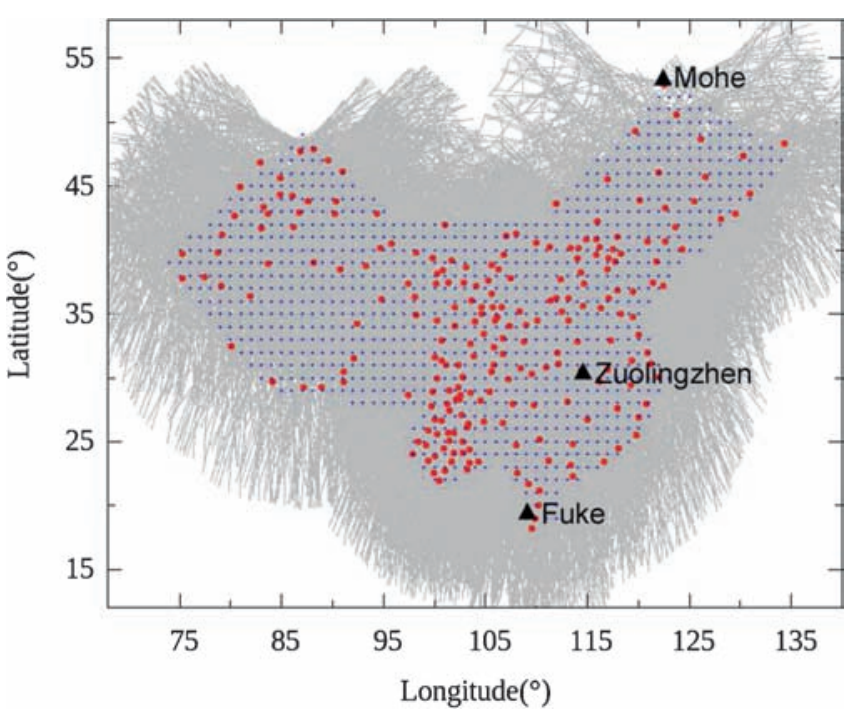

Figure 1. Geographical locations of the ionosondes and GPS receivers used in this work (red dots show the locations of the GPS receivers and blue dots depict the locations that are selected for comparison of GPS TEC with IRI-TEC prediction over China).

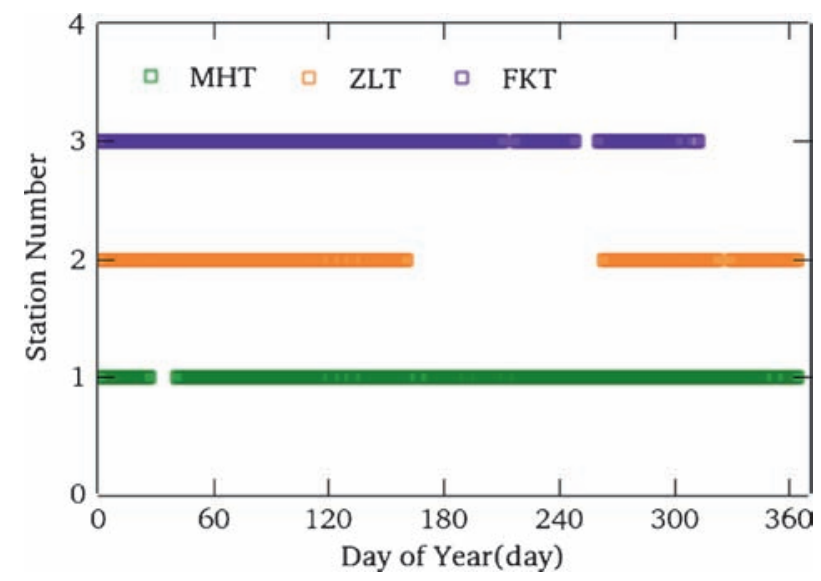

Figure 2. Temporal distribution of available data at the three stations in the year 2011. 


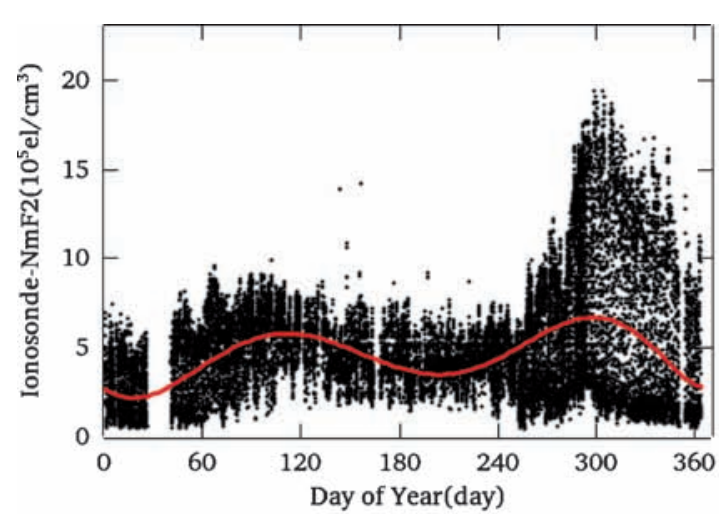

(a) $\mathrm{NmF} 2$ at $\mathrm{MH}$ in 2011

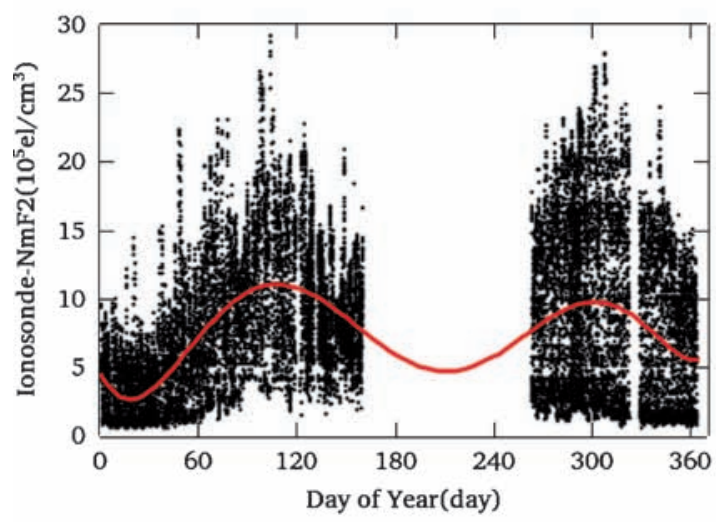

(c) NmF2 at ZLZ in 2011

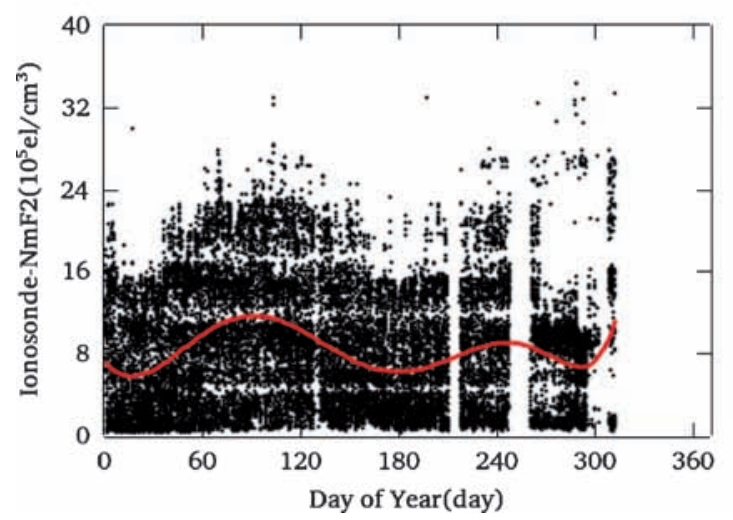

(e) NmF2 at FK in 2011

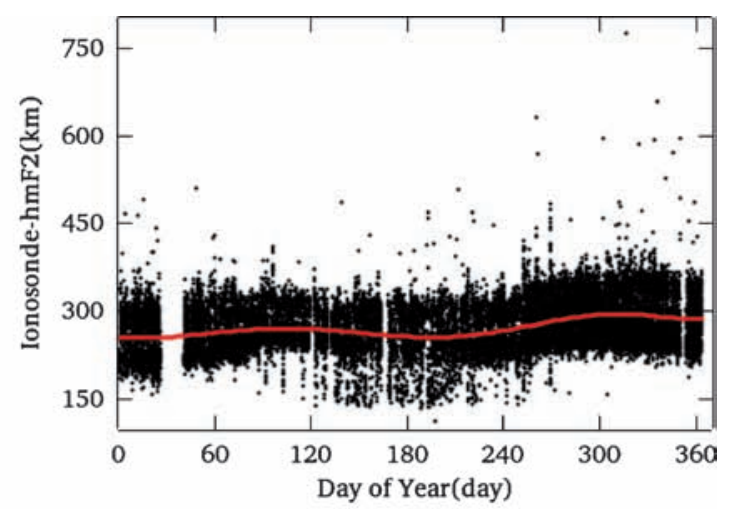

(b) hmF2 at MH in 2011

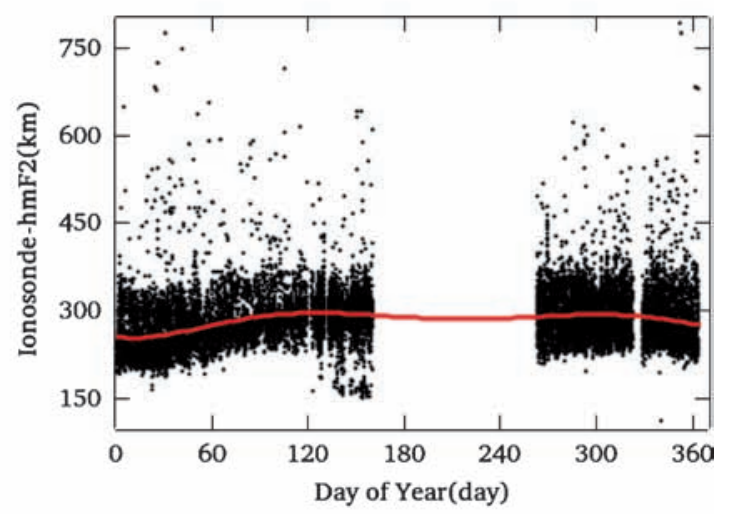

(d) hmF2 at ZLZ in 2011

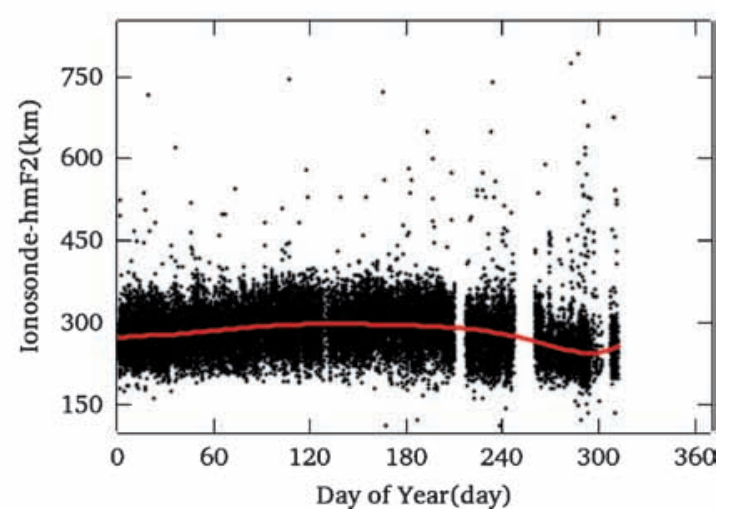

(d) hmF2 at FK in 2011

Figure 3. Observed NmF2 and hmF2 values at MH, ZLZ, and FK stations.

The vertical TEC (VTEC) values can be calculated from the carrier phase-smoothed code measurements of two frequencies L1 and L2 as well as the differential code bias of the satellites and receivers by equation (1) (Blewitt 1990; Miyazaki et al. 1997; Ma and Maruyama 2003).

$$
\begin{aligned}
P_{1}-P_{2}= & \frac{40.3\left(f_{2}^{2}-f_{1}^{2}\right)}{f_{1}^{2} f_{2}^{2}} * m f(z) * \mathrm{VTEC} \\
& +c\left(D C B_{r}+D C B_{s}\right)
\end{aligned}
$$

In equation (1), $P_{1}$ and $P_{2}$ are the carrier phasesmoothed code measurements, $f_{1}$ and $f_{2}$ are the carrier frequencies of the L1 and L2 signals, respectively, $c$ is the speed of light, $m f$ is the ionospheric mapping function depending on the zenith distance $z$ at the station, VTEC is the vertical TEC at the IPP, $D C B_{r}$ and $D C B_{s}$ are the differential code biases of the receiver and satellite, respectively.

A polynomial function is used to build a regional TEC model over China, as shown by equation (2) (Coster et al. 1992),

$$
\begin{aligned}
\mathrm{VTEC} & =\sum_{i=0}^{n} \sum_{j=0}^{m} E_{i j}\left(\varphi-\varphi_{0}\right)^{i}\left(s-s_{0}\right)^{j}, \\
s-s_{0} & =\left(\lambda-\lambda_{0}\right)+\left(t-t_{0}\right) * \frac{\pi}{12}
\end{aligned}
$$


where $n$ and $m$ are the polynomial degree and order of the model, respectively, $E_{i j}$ are the polynomial term coefficients, $\varphi$ and $\lambda$ are the latitude and longitude of the IPP, respectively, $\varphi_{0}, \lambda_{0}$ are the latitude and longitude of the expansion point, which is typically the central location in the local area, $t$ is the observation time in hours, and $t_{0}$ is the central time of the model interval.

To quantitatively evaluate the degree of agreement between the observed values and the IRI predicted values, we use several criteria including mean difference (hereafter referred to as MD), root mean square error (RMSE) (Ikubanni et al. 2014), and relative deviation module mean (RDMM) (Bertoni et al. 2006; Oyeyemi et al. 2013). They are calculated according to the following expressions:

$$
\begin{gathered}
\mathrm{MD}=\frac{1}{n} \sum_{i=1}^{n}\left(X_{\mathrm{OBS}}-X_{\mathrm{IRI}}\right) \\
\mathrm{RMSE}=\sqrt{\frac{1}{n} \sum_{i=1}^{n}\left(X_{\mathrm{OBS}}-X_{\mathrm{IRI}}\right)^{2}} \\
\mathrm{RDMM}=\frac{1}{n} \sum_{i=1}^{n} \frac{\left|X_{\mathrm{OBS}}-X_{\mathrm{IRI}}\right|}{X_{\mathrm{OBS}}}
\end{gathered}
$$

where $n$ is the number of data points and $X_{\mathrm{OBS}}$ and $X_{\text {IRI }}$ are the observed and IRI predicted values, respectively.

\section{Results and discussion}

\subsection{Comparison of NmF2 and hmF2}

In this work, the ionograms derived from ionosondes are updated every $15 \mathrm{~min}$. The $\mathrm{NmF} 2$ values are converted from the obtained F2-layer critical frequency (foF2) according to equation (6):

$$
\mathrm{NmF} 2=\frac{1}{81}(\text { foF } 2)^{2} * 10^{6}
$$

where foF2 is the F2-layer critical frequency in $\mathrm{MHz}$ and $\mathrm{NmF} 2$ is in $\mathrm{el} / \mathrm{cm}^{3}$.

Comparison of the observed NmF2 and hmF2 at the three ionosondes with IRI models (IRI2007 and IRI2012) predictions are investigated. Figures 4 and 5 show a correlation between the observed NmF2 and hmF2 values and IRI predicted values, respectively. The red lines in the figures show the fitting equations estimated by least square estimation. In figure 4 , the red curves show the fitting equations by 9 th order polynomial fit of observed NmF2 values and IRI predictions. And the goodness-of-fit is presented in each subfigure by the index ' $R$ '. In figure 5 , the equations of the red lines are shown in the bottom right corner of each subfigure in the form ' $y=a x+b$ ', and ' $a$ ' is the slope of linear equation. The results of comparison are tabulated in tables 1 and 2, which quantitatively show the agreements between the observed values and IRI predictions.

As figure 4 demonstrates above, there are certain linear correlations between the observed $\mathrm{NmF} 2$ values at the three stations with the IRI model predicted values, especially at the ZLZ station that is located in the mid-latitude region. In contrast, the NmF2 values obtained from the FK station, which is located at $19.5^{\circ} \mathrm{N}$ (dip angle $27.083^{\circ} \mathrm{N}$ ) near the equatorial anomaly region of the ionosphere, are not in significant agreement with the IRI predictions. This less correlation could be influenced by solar activity. Another factor that would be, strength of the equatorial electrojet (EEJ) which affects the ionization in the equatorial anomaly region. Although FK station is not very close to equatorial ionization anomaly (EIA), the effect of EEJ may extend to latitudes beyond the EIA crest on strong EEJ days (Sethia et al. 1980). From the perspective of correlation coefficients, the precision of the NmF2 values predicted by IRI2012 is significantly improved compared with that of IRI2007. Table 1 shows the difference between the observed $\mathrm{NmF} 2$ values and the IRI model predictions by MD, RMSE, and RDMM. From these statistic variables, IRI2012 has greater agreement with the observed values than IRI2007. The MD values between the observed values at the three stations and IRI2007 predictions are negative, which indicates that IRI2007 overestimates the NmF2 values. IRI2012 has strong improvement because the absolute MD values become smaller, especially the ZLZ-MD value, which is just $0.20 * 10^{5} \mathrm{el} / \mathrm{cm}^{3}$. Additionally, the RMSE values by IRI2012 nearly reduce by $50 \%$ compared with IRI2007. The RMDD values for the three stations also decreased remarkably, especially at the FK station.

As depicted in figure 5, there are significant linear correlations between the observed $\mathrm{hmF} 2$ values at the three stations and the IRI model predictions. All of the linear correlation coefficients are nearly 1 . The degree of correlation between the observed hmF2 values and the IRI2012 predicted values is slightly higher compared to IRI2007. Table 2 shows the difference between the observed hmF2 values and the IRI model predictions by MD, RMSE, and RDMM. From the MD values in table 2, the IRI2007 model overestimates hmF2 at the three stations. The IRI2012 model overestimates the $\mathrm{hmF} 2$ values at the $\mathrm{MH}$ and $\mathrm{FK}$ stations and underestimates the hmF2 values at the ZLZ 


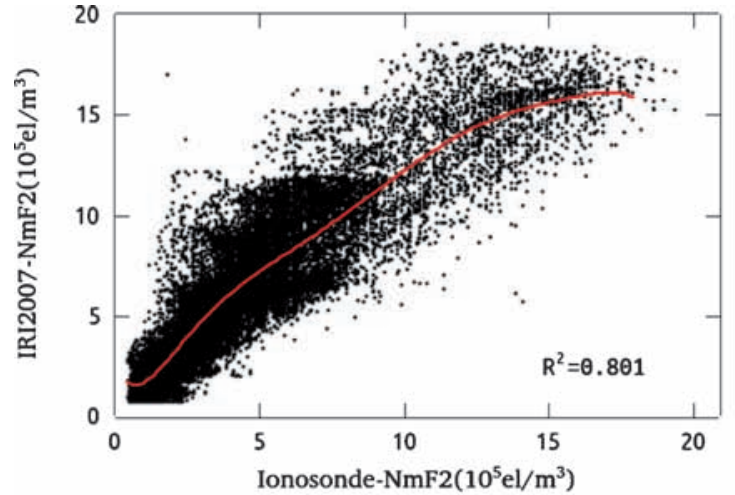

(a) $\mathrm{NmF} 2$ at $\mathrm{MH}$ compared with IRI2007

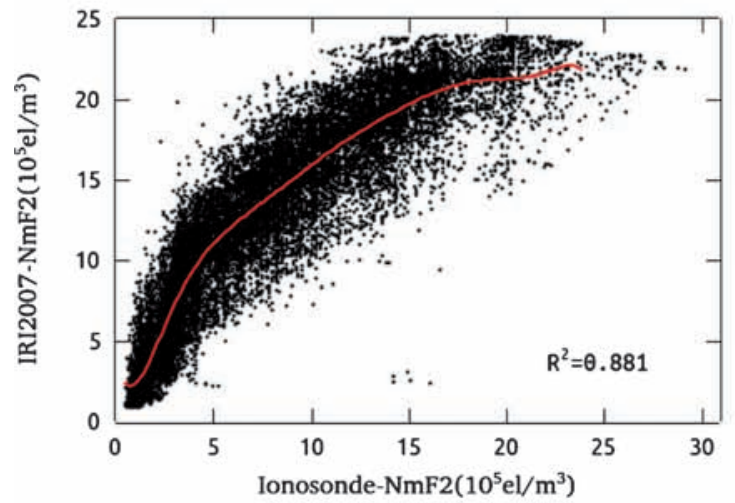

(c) NmF2 at ZLZ compared with IRI2007

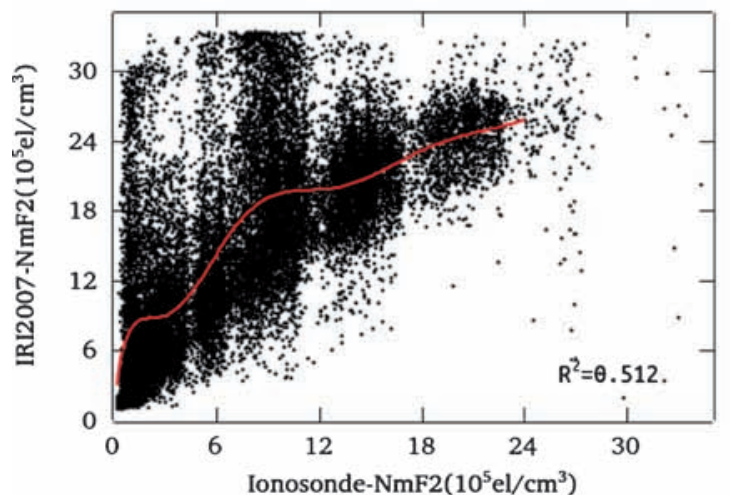

(e) NmF2 at FK compared with IRI2007

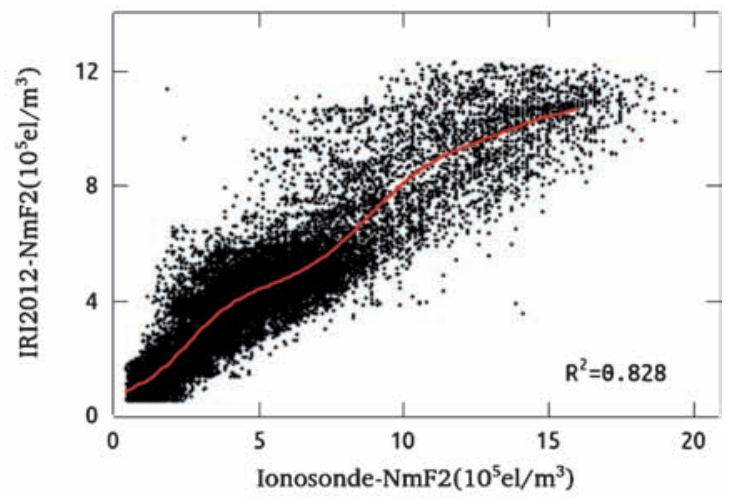

(b) $\mathrm{NmF} 2$ at $\mathrm{MH}$ compared with IRI2012

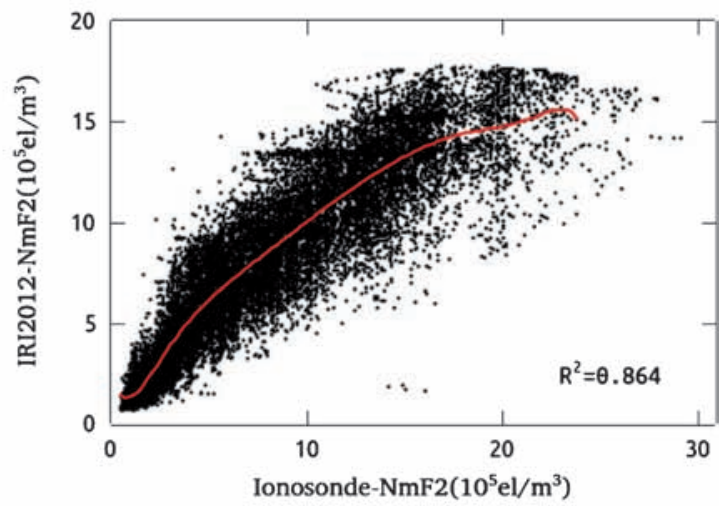

(d) NmF2 at ZLZ compared with IRI2012

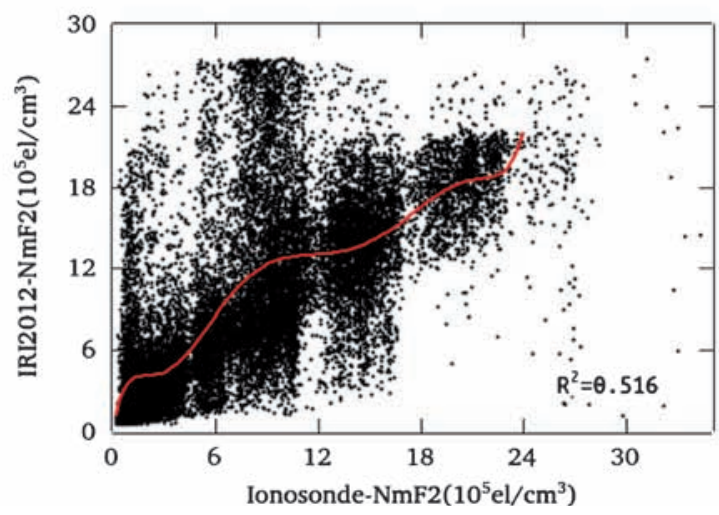

(d) NmF2 at FK compared with IRI2012

Figure 4. Comparison of observed NmF2 values at the three stations with IRI model.

station, which is located in the middle latitude region. The RMSE values are $\sim 30 \mathrm{~km}$ at the $\mathrm{MH}$ station and ZLZ station and $50 \mathrm{~km}$ at the FK station. At the same time, RDMM values by IRI2012 are reduced by $\sim 1-3 \%$ compared with IRI2007. Thus, the degree of agreement between the observed values and IRI2012 predictions is higher than that of IRI2007. This obvious improvement of IRI2012 model probably benefit from new global models for the F2 peak parameters. Neural network (NN) technique is used for development of the F2 peak parameters (Bilitza et al. 2011). It can make full use of the history data and predict non-linear relationships. Development and evaluation of the NN model will be tested and compared to ensure the predictions to a greater accuracy. For detailed information on the NN model and testing of foF 2 values, the reader is referred to these former works (Haykin 1994; Oyeyemi et al. 2005). Along with time, more and more data will be added to NN re-trained. So we believe that the F2 peak parameters from IRI model and observed values will have great consistency in the future.

\subsection{Comparison of TEC over China}

In this section, we compare TEC values at the 999 locations (blue points) as shown in figure 1 between GPS TEC and IRI2012 model predictions. 


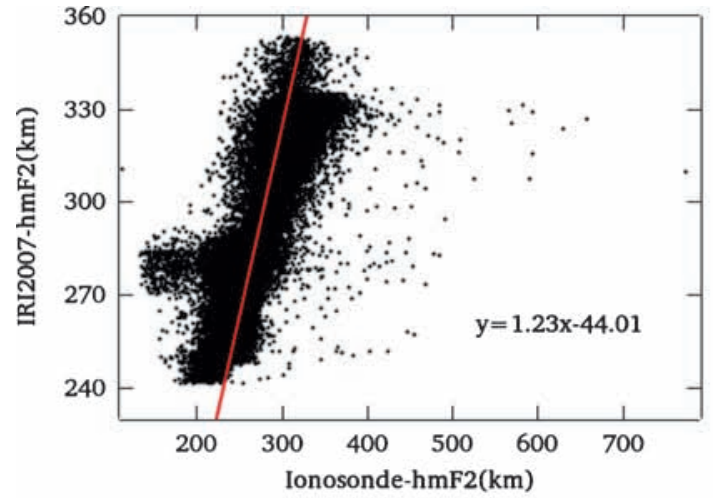

(a) hmF2 at MH compared with IRI2007

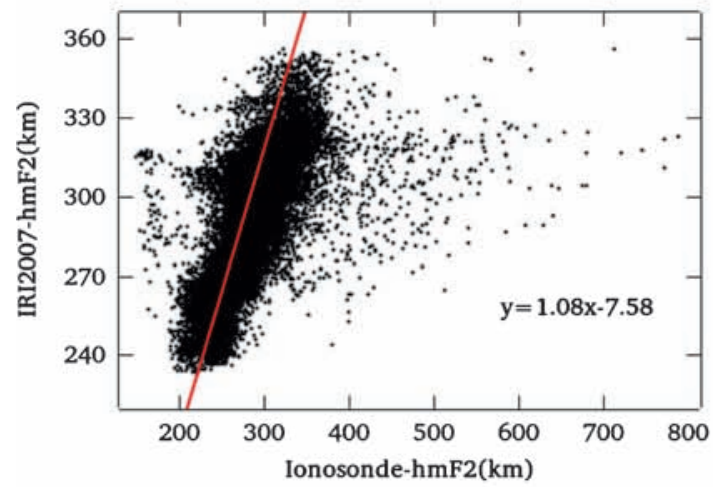

(c) hmF2 at ZLZ compared with IRI2007

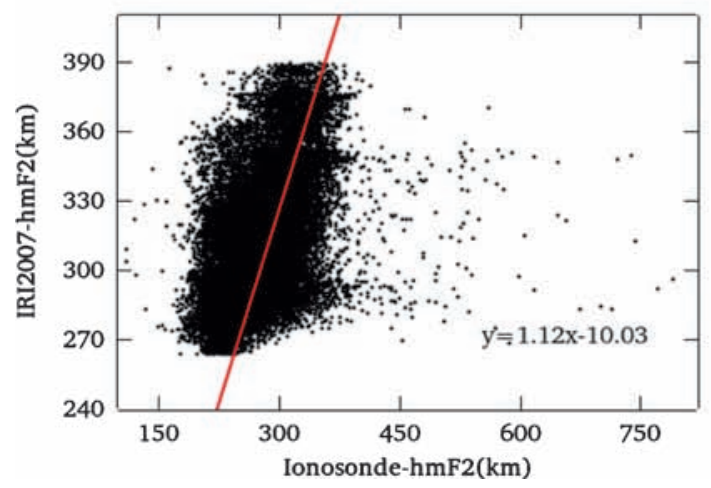

(e) hmF2 at FK compared with IRI2007

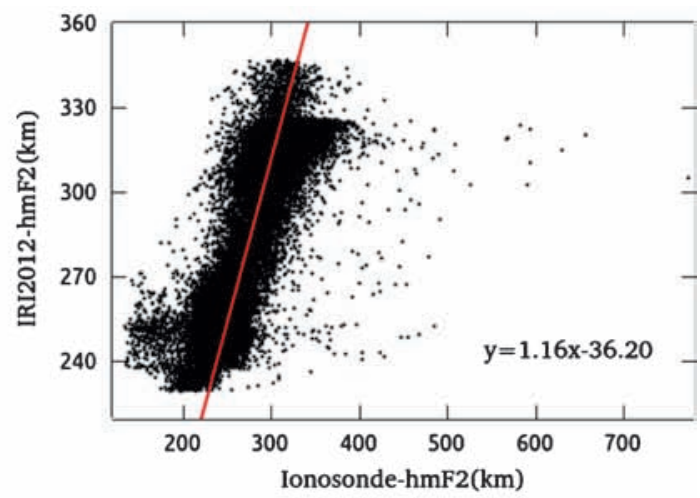

(b) hmF2 at MH compared with IRI2012

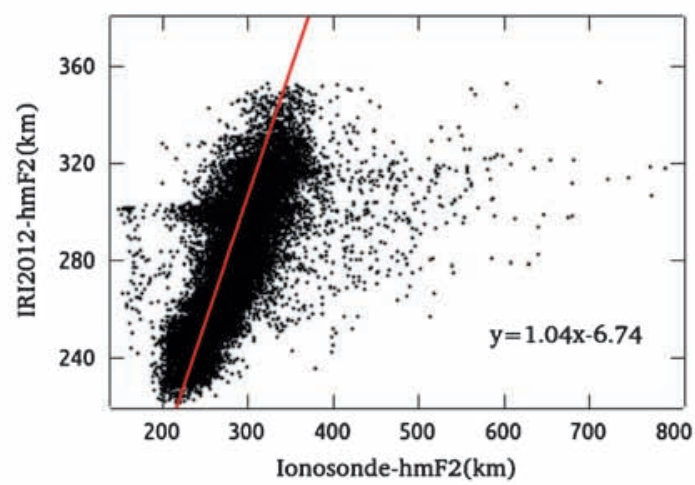

(d) hmF2 at ZLZ compared with IRI2012

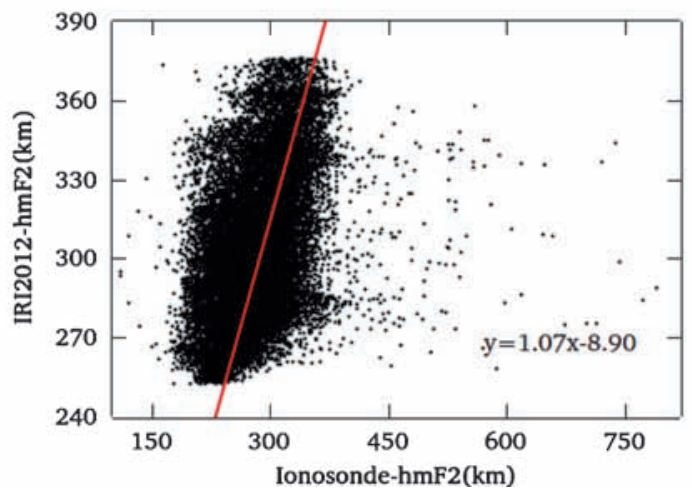

(f) hmF2 at FK compared with IRI2012

Figure 5. Comparison of the observed hmF2 values at the three stations with IRI model.

Table 1. Comparison of observed NmF2 at the $M H, Z L Z$, and FK with IRI200'7 and IRI2012.

\begin{tabular}{lcccc}
\hline Station & IRI model & $\begin{array}{c}\text { MD } \\
\left(10^{5} \mathrm{el} / \mathrm{cm}^{3}\right)\end{array}$ & $\begin{array}{c}\text { RMSE } \\
\left(10^{5} \mathrm{el} / \mathrm{cm}^{3}\right)\end{array}$ & $\begin{array}{c}\text { RDMM } \\
(\%)\end{array}$ \\
\hline MH & IRI2007 & -1.70 & 2.46 & 51.05 \\
& IRI2012 & 0.75 & 1.65 & 24.90 \\
ZLZ & IRI2007 & -4.45 & 5.29 & 86.92 \\
& IRI2012 & 0.20 & 2.36 & 25.64 \\
FK & IRI2007 & -7.17 & 9.33 & 207.44 \\
& IRI2012 & -1.41 & 5.12 & 83.71 \\
\hline
\end{tabular}

The GPS TEC values are estimated by a polynomial model (equation 2) with 6th degree and 6th order. The IRI-TEC values are calculated by the
Table 2. Comparison of the observed hmF2 at $M H, Z L Z$, and FK with IRI2007 and IRI2012.

\begin{tabular}{lcrcr}
\hline Station & IRI model & $\begin{array}{c}\text { MD } \\
(\mathrm{km})\end{array}$ & $\begin{array}{c}\text { RMSE } \\
(\mathrm{km})\end{array}$ & $\begin{array}{r}\text { RDMM } \\
(\%)\end{array}$ \\
\hline MH & IRI2007 & -19 & 35 & 10.64 \\
& IRI2012 & -7 & 27 & 7.62 \\
ZLZ & IRI2007 & -4 & 35 & 7.70 \\
& IRI2012 & 5 & 34 & 6.99 \\
& IRI2007 & -33 & 54 & 16.60 \\
& IRI2012 & -23 & 48 & 14.11 \\
\hline
\end{tabular}

integration of the electron density profile of the IRI2012 model. It is known that the IRI model only provides a profile of up to $2000 \mathrm{~km}$ altitude, 
while there is an additional 10 20\% TEC beyond the $2000 \mathrm{~km}$ altitude (Makela et al. 2000). Therefore, we extended the profiles to $\sim 20,000 \mathrm{~km}$, the orbit height of the GPS satellites, using an exponential decay function to fit the topside (Matteo and Morton 2010):

$$
f(h)=y_{i} e^{k\left(h-h_{i}\right)}
$$

where $f(h)$ is the electron density at $h \mathrm{~km}$ altitude, $y_{i}$ is the electron density at $h_{i} \mathrm{~km}$ altitude, $e$ is the base number of natural logarithm, and $k$ is the decay factor to be estimated. In this study, we use 100 samples of electron density under the $2000 \mathrm{~km}$ with $1 \mathrm{~km}$ step size to fit the topside by least square estimation. When the decay factor $k$ is estimated, electron densities beyond $2000 \mathrm{~km}$ can be extrapolated by equation (7).

Solar and geomagnetic activities significantly influence the TEC values of ionosphere. Some indices including Kp index, Dst index and Sunspot number (SSN) in the year 2011 are shown in figure 4. The solar data (SSN) and Kp indices have been obtained from Space Weather Prediction Center of NOAA (website: http://www.swpc.noaa. gov). The Dst indices are obtained from the website of World Data Center for Geomagnetism, Kyoto, Japan (http://wdc.kugi.kyoto-u.ac.jp). The black lines in figure 6 show the daily mean values of $\mathrm{Kp}$ indices, Dst indices and SSN respectively. The red lines are the 9 th order polynomial fit of these indices respectively. Most of $\mathrm{Kp}$ indices are $\sim 2$ in year 2011 except for few days beyond 5. Dst indices are relatively steady, approximately $-10 \mathrm{nT}$. Only a few days of that are lower than $-50 \mathrm{nT}$. While, sunspot numbers are $<100$ through the whole year 2011. From these indices in 2011, we know that the year 2011 is in a low solar activity period.

The GPS TEC values and IRI-TEC values at the 999 points are calculated day-by-day at 2-hr intervals for the year 2011 (number of each group samples: $999 *(24 / 2) * 365=4375620)$. The differences between them are depicted by MD, RMSE, and RDMM values as shown in figures 7,8 , and 9. The red line through the black points is the 9 th order polynomial fit.

According to the results presented in figure 7, the variation of MD values is dependent on seasons. It has to be noted that we use the dates of the equinoxes and solstices to mark the beginning and end of the seasons in a year. Most of the MD values in early spring are positive, which means the IRI2012 model gives an underestimation of the electron density in early spring. Subsequently, the IRI2012 model overestimates the electron density in later spring. On the other hand, the IRI2012 model overestimates the electron density in summer. The MD values are negative for almost the entire summer. In autumn, the negative

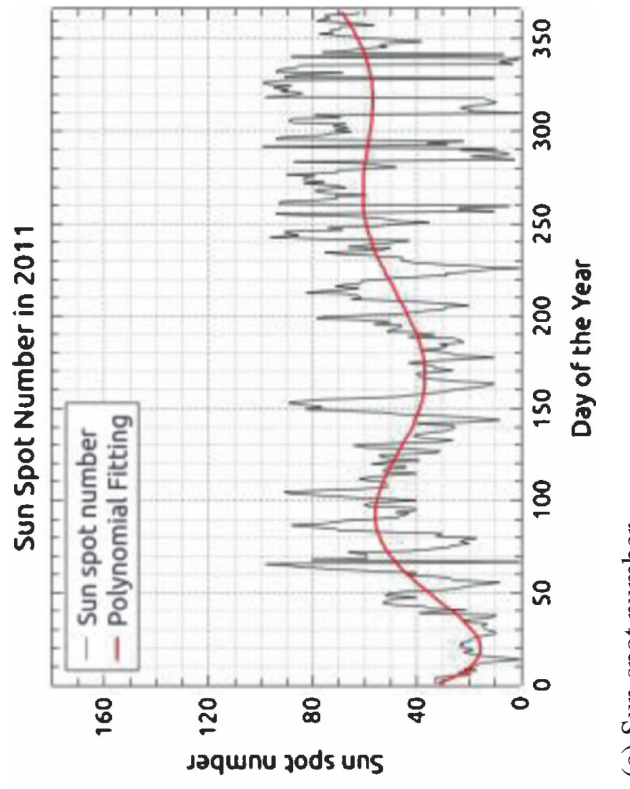

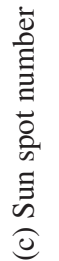
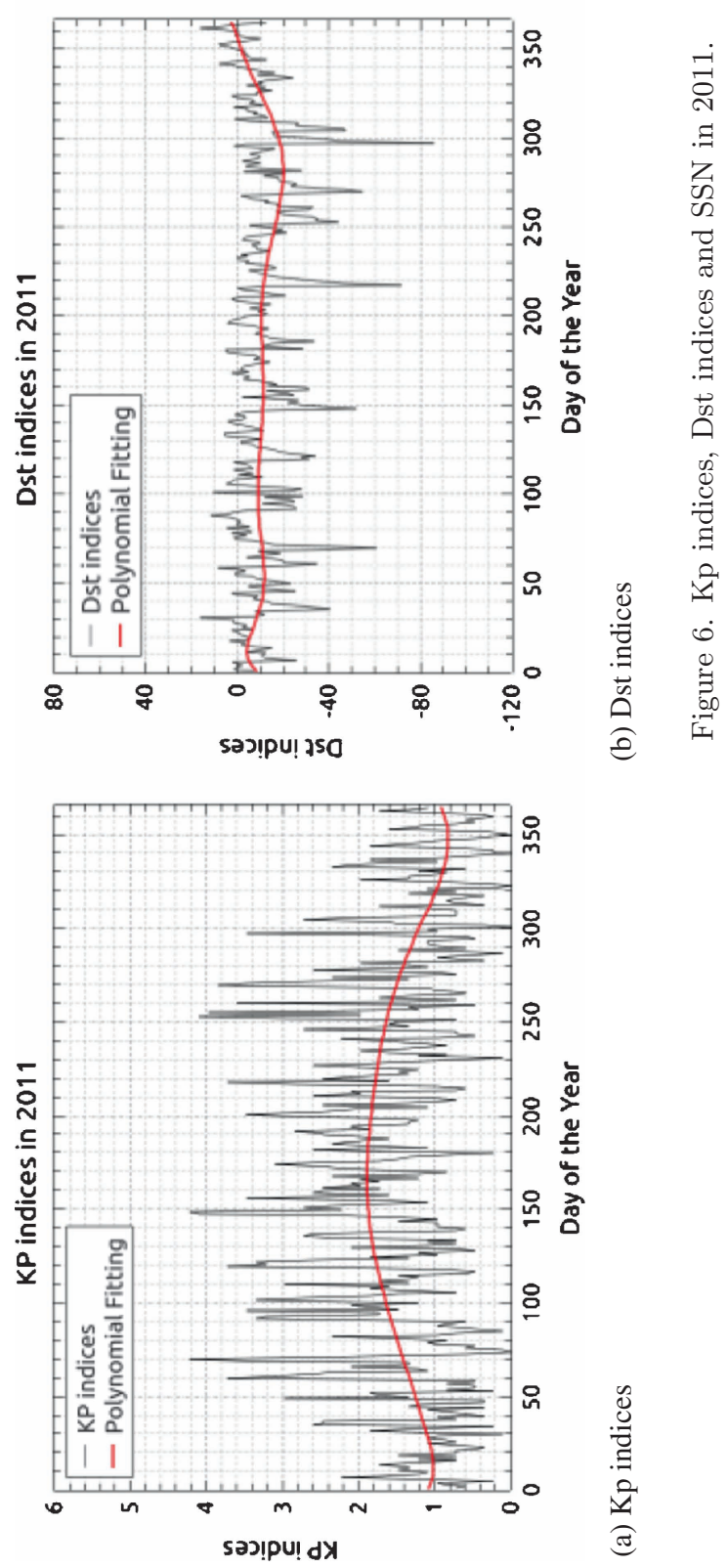


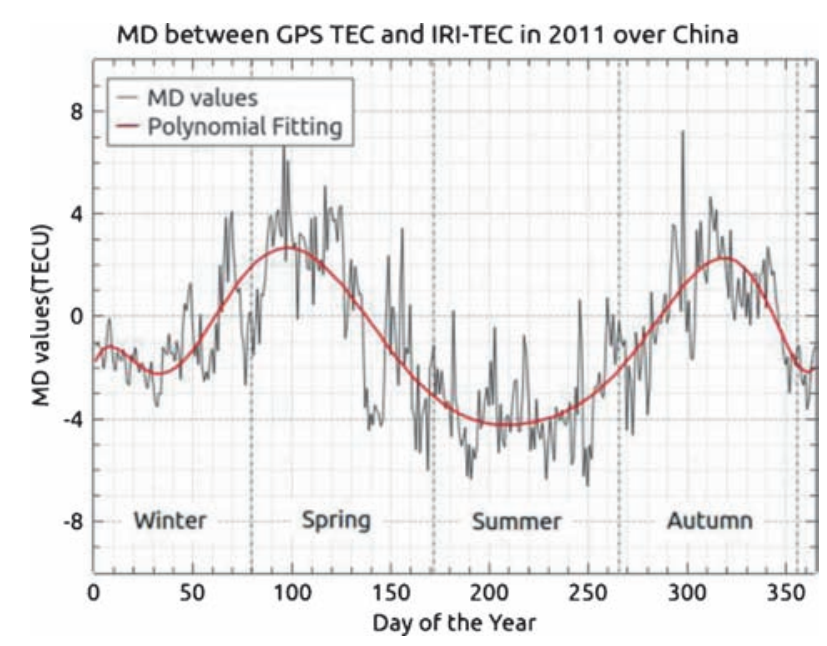

Figure 7. MD between GPS TEC and IRI-TEC in 2011 over China.

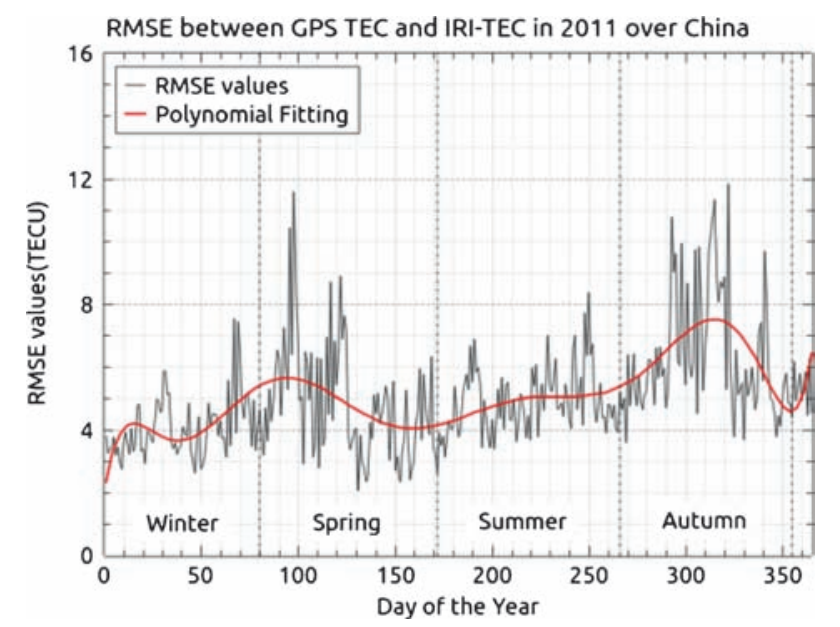

Figure 8. RMSE between GPS TEC and IRI-TEC in 2011 over China.

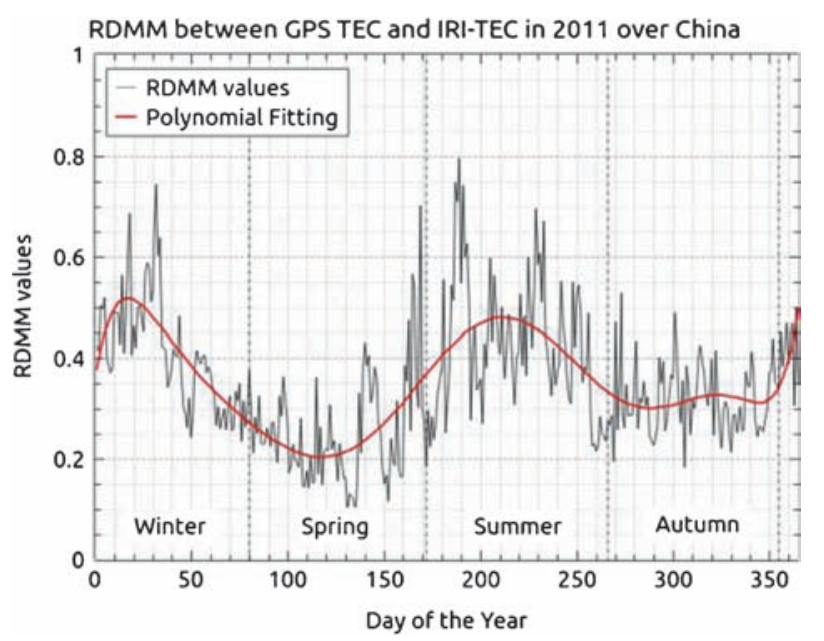

Figure 9. RDMM between GPS TEC and IRI-TEC in 2011 over China. and positive values are 50:50. The MD values in winter are mostly negative. The maximum MD values, $\sim 7$ TECU, occur in spring and autumn. The minimum MD values, near -7 TECU, appear in summer. Likewise, the absolute values of the MD values in winter are apparently smaller than those in other seasons.

There is no significant correlation between RMSE values variation with the seasons as shown in figure 8. Most of the RMSE values are $\sim 5$ TECU, except some values that are beyond 10 TECU in spring and autumn. The minimum RMSE values are $\sim 2$ TECU and occur in spring and summer. The maximum RMSE values are near 12 TECU and occur on some days in spring and autumn. Obviously, lots of RMSE values in autumn are larger than that in other seasons. In other words, the degree of agreement between GPS TEC and IRI-TEC in autumn is lower compared with other seasons.

It is clear that the RDMM values are different in each season as shown in figure 9. Compared with other seasons, RDMM values in spring are smaller. The minimum RDMM is $\sim 10 \%$. In autumn, the RDMM values are relatively stable at $\sim 30 \%$. However, the RDMM values are bigger in summer and winter. Some values are greater than $60 \%$, especially in summer with a maximum of $\sim 80 \%$.

In general, the results of the calculation by MD, RMSE, and RDMM show a good agreement between GPS TEC and IRI-TEC in 2011 over China. The difference between the GPS TEC and IRI2012 model predictions is quite dependent on seasons. The IRI2012 model underestimates electron density in spring and the latter part of autumn and overestimates electron density in the first half of autumn and winter. Referring to GPS TEC, the precision of IRI-TEC can be expressed by RMSE values. The precision of the IRI2012 model predictions is $\sim 5$ TECU mostly in the year 2011 except some days beyond 10 TECU in spring and autumn. Although RDMM values do not show precision of the IRI model directly, the relative deviations are helpful to correct the IRI predictions in the future.

\subsection{Comparison of TEC at the MH, ZLZ, and FK stations}

In this part of our work, we compare the monthly mean values between the GPS TEC and IRI2012 predicted values at the MH, ZLZ, and FK stations. Figure 10 shows the IRI-TEC monthly means in 2011 at the three stations. In addition, there are two obvious discontinuities of IRI-TEC as depicted in figure 11.

As figure 10 shows above, the IRI-TEC monthly means varied largely at the MH, ZLZ, and FK 


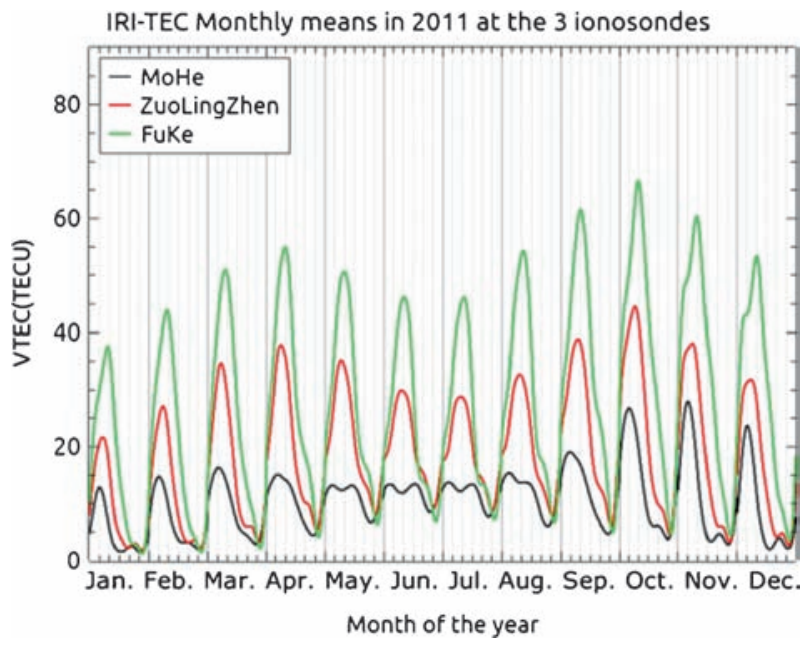

Figure 10. IRI-TEC monthly means at the MH, ZLZ, and FK stations in 2011.

stations that are located in middle-high, middle-low, and low latitudes, respectively. The TEC values at the FK station are nearly twice of those at the ZLZ station and a few times greater than those at the MH station, mostly during $24 \mathrm{hrs}$ in each month. All of the maximum TEC values at the three stations appear in October or November, and the minimum values appear in January. The maximum values of TEC at the three stations in summer are smaller than those in spring and autumn. On the contrary, the minimum values of TEC in summer are larger than those in other seasons. Night-time enhancements apparently occur in January, February, March, October, November, and December at the MH and ZLZ stations. The noon bite-out phenomenon is clearly shown in May, June, July, and August at The MH station. The IRI-TEC depicts a double peak in diurnal values at the $\mathrm{MH}$ station, a feature which is not observed at the ZLZ and FK stations.

From the comparison of the IRI-TEC monthly means, we found two discontinuities occurring at the beginning of November and December from the year 2000 to 2015 as depicted in figure 11. The first discontinuity between October and November happens in every year at ZLZ station and FK station. While at the MH station, the discontinuity happens in solar minimum, and does not happen in solar maximum. The other discontinuity between November and December obviously happens in every year. The first moment appeared in November, which caused a bias of 3 TECU between October and November in 2011 at the MH and ZLZ station, which is not apparent at the FK station. The second moment of discontinuity of IRITEC appeared in December, which caused a bias of 3 TECU between November and December at the MH and ZLZ stations and a bias of 2 TECU at the FK station. The determination of these discontinuities in IRI-TEC monthly means is further used to update the IRI model.

In addition, GPS TEC values at the MH, ZLZ, and FK stations in 2011 are estimated and compared with the IRI2012 model predicted values as shown in figures 12-14. The IRI2012 model overestimates the electron density at the MH station mostly in 2011, especially in the summer. As has been shown in the comparison of TEC values from January to September, the IRI model does not necessarily present the actual variation of the TEC values. However, the variations of the TEC values in October, November and December are represented relatively correctly by the IRI model, although some differences between them are relatively large. A possible explanation is that there are not enough IPP distributions over the MH station. As a result, some GPS TEC values estimated by the polynomial model are negative. The percentage of occurred negative TEC values and the minimum values in each month as well as monthly mean of these values are shown in figures 15 and 16 , respectively. According to figure 15, it has an obvious higher probability of appearing negative GPS derived TEC values in later - autumn and winter than those in spring and summer, especially in January and February; while, the minimum TEC value is approximately -13 TECU in November as shown in figure 16. In that case, we refined the GPS-TEC values at MH station as depicted in figure 17 by keeping the monthly minimum values to zero and raising the other by the same amount. At the ZLZ station, there is strong agreement between GPS TEC and IRI-TEC. The IRI-TEC and GPS TEC are very close in the entire year 2011. The maximum difference is $\sim 5$ TECU. At the FK station, the IRI2012 model also represents a familiar trend of TEC values except some underestimation in daytime in spring and winter. The biggest difference is $\sim 30$ TECU, which would be caused by an equatorial ionization anomaly.

In order to investigate further, the differences between IRI-TEC and GPS-TEC are calculated, as well as the standard deviation of monthly mean of GPS derived TEC at the three stations as shown in figures 18-20. In these figures, the green lines depict the difference between IRI-TEC and GPSTEC, and the blue and red lines describe the three standard deviations. Also, the annual mean values of the three standard deviations are presented by grey dot-dash lines. It should be noted that the standard deviations of GPS derived TEC are 2.68, 3.19 and 5.97 TECU at MH, ZLZ and FK stations, respectively. From figures $18-20$, it is known that most different values lie within three standard deviations of GPS-TEC. The proportions of the different values beyond three standard deviations 

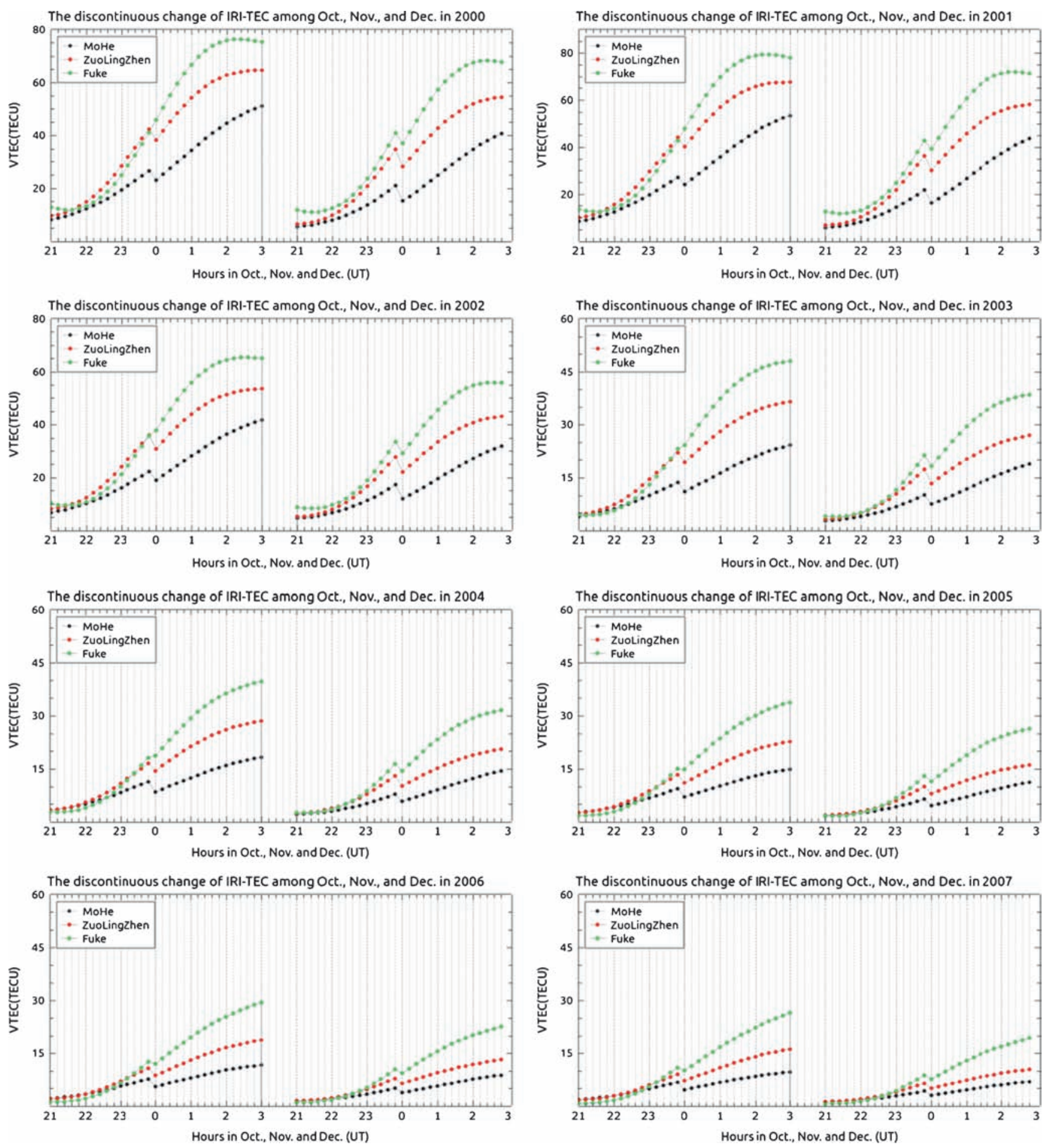

Figure 11. Discontinuities of IRI-TEC monthly means among October, November, and December from 2000 to 2015.

are $19.38 \%, 7.08 \%$ and $3.82 \%$ at MH, ZLZ and FK stations, respectively. Thus we consider IRI2012 model could give proper predictions within the actual TEC variations.

\subsection{Discussion}

We have compared $\mathrm{NmF} 2, \mathrm{hmF} 2$, and TEC values obtained by GPS measurements and ionosondes at
MH, ZLZ, and FK stations with IRI model, respectively. Some common features could be known from the comparison. The monthly mean diurnal TEC values are higher in equinoctial months than that in solstice. Olwendo et al. (2013) mentioned that thermospheric neutral composition has direct contr'ol on the seasonal variations of TEC. The meridional wind changes the neural composition and $\mathrm{O} / \mathrm{N}_{2}$ ratio. Bhuyan and Borah (2007) found 

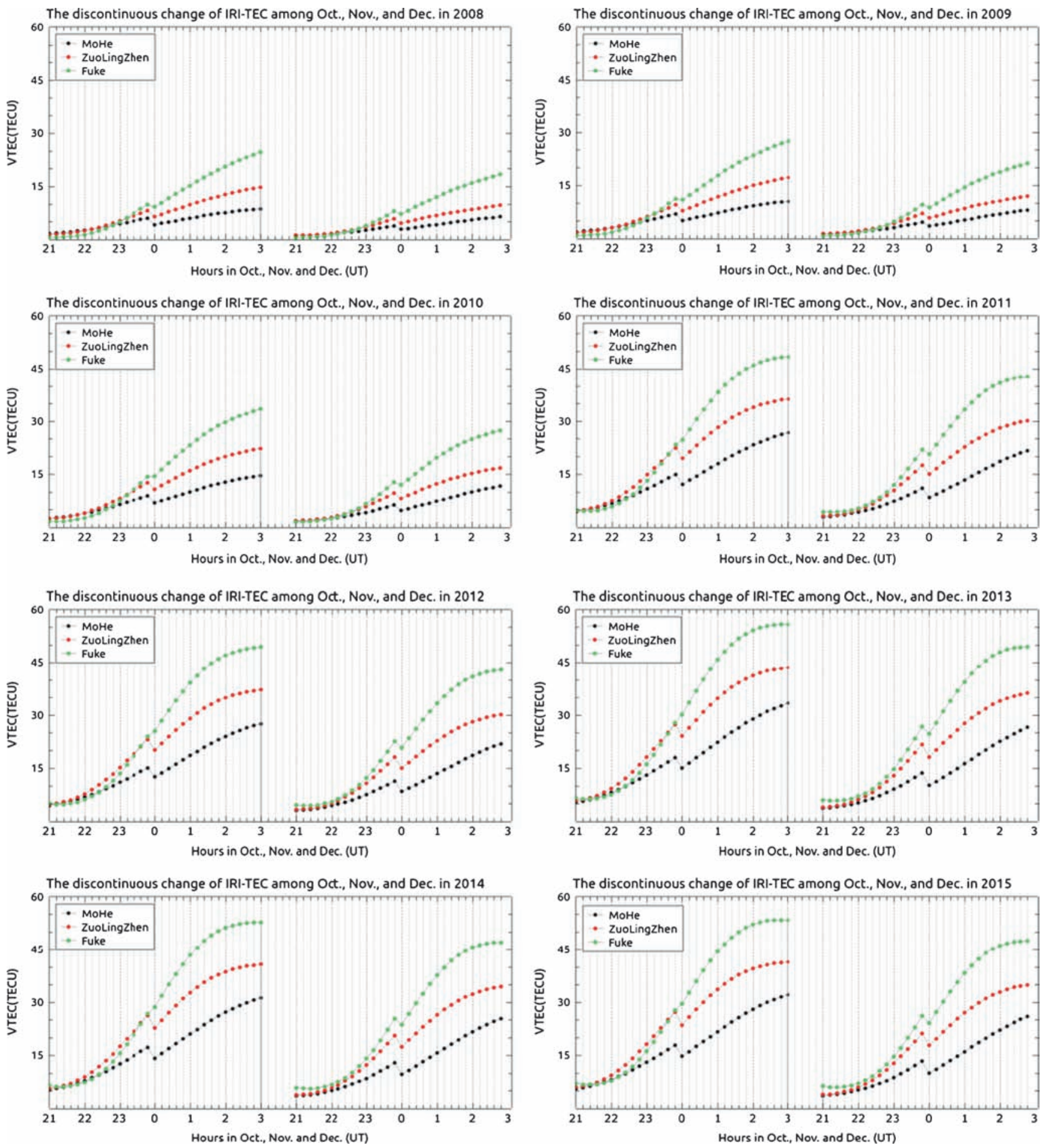

Figure 11. (Continued.)

winter anomaly in the high solar activity period of 2011-2012 would be the higher thermospheric $\mathrm{O} / \mathrm{N}_{2}$ ratio in winter months as compared to that in summer months. $\mathrm{O} / \mathrm{N}_{2}$ ratio will be maximum in equinox, then result in higher electron density and thus equinox TEC will be higher (Bagiya et al. 2009).

McNamara (1984) tested IRI model for low, middle, and high latitude in the Northern Hemisphere and found that the model is capable of representing the observed TEC well in middle and high latitudes but not well at low latitudes. Abdu et al. (1996) investigated the IRI model in Brazilian sector and got a similar result. In this work, we also found the same situation over China. The diurnal hourly variation of TEC values is higher at low latitude and lower at high latitude as shown by standard deviations in figures 18-20. Kenpankho et al. (2013) compared 


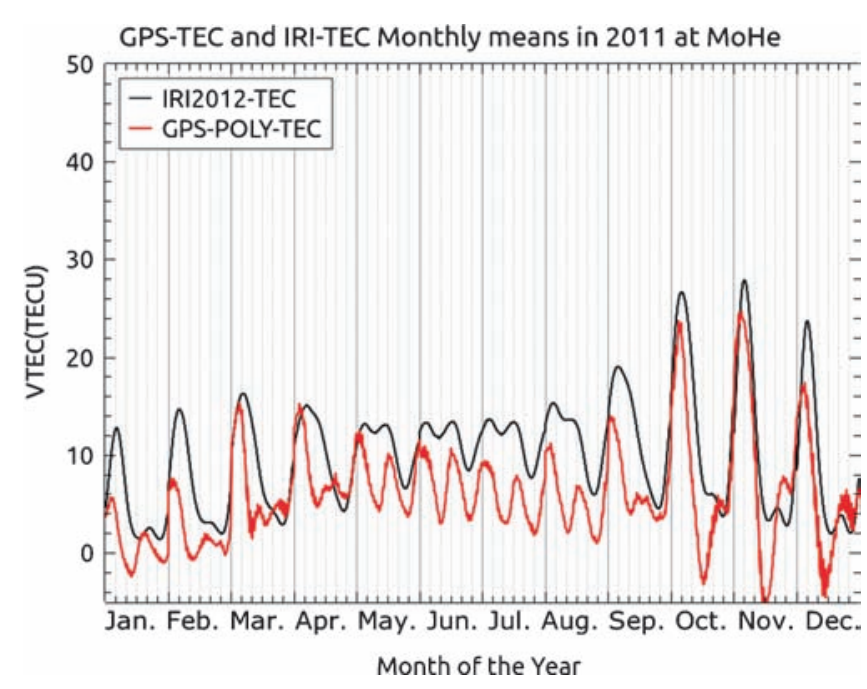

Figure 12. Comparison of GPS TEC and IRI-TEC at the MH station.

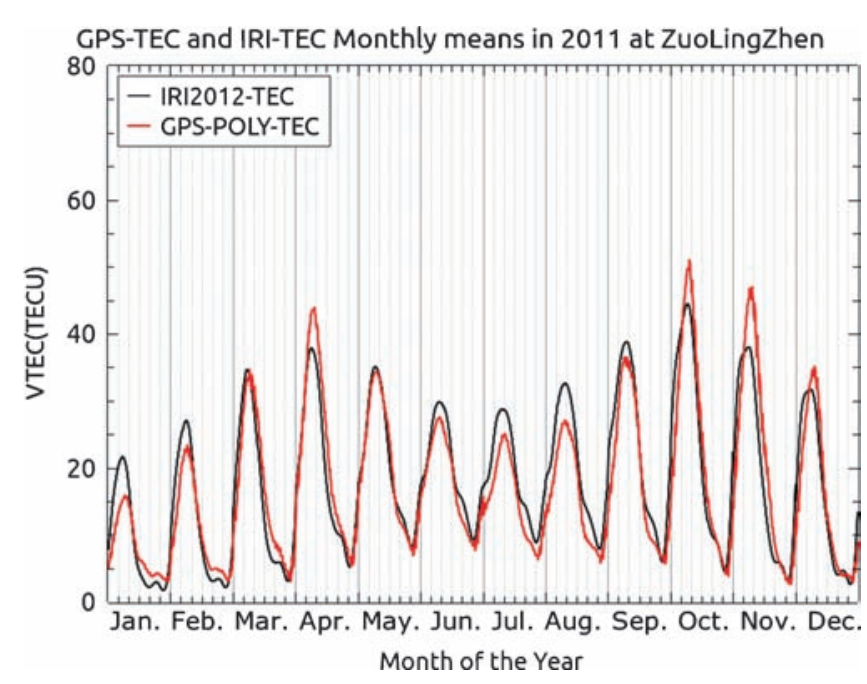

Figure 13. Comparison of GPS TEC and IRI-TEC at the ZLZ station.

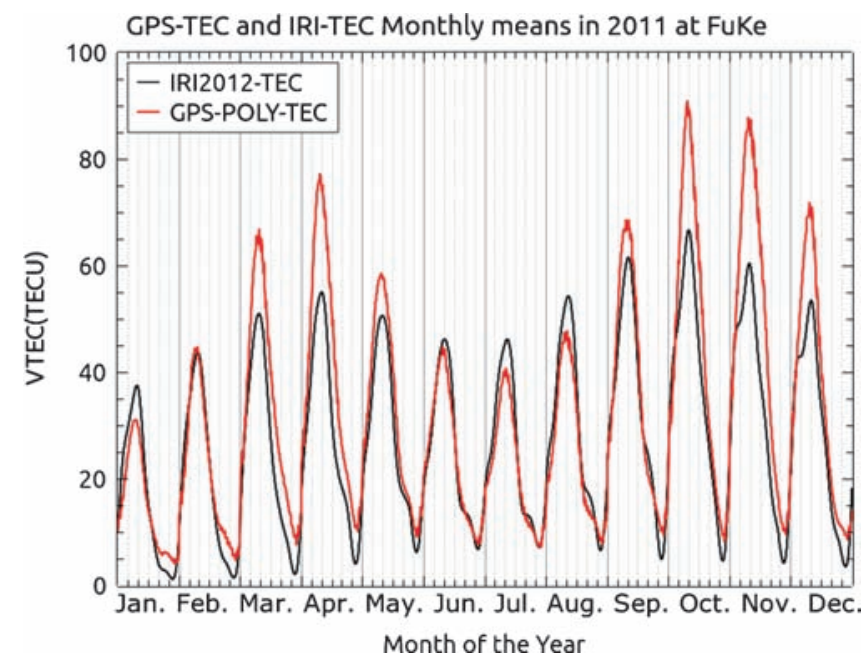

Figure 14. Comparison of GPS TEC and IRI-TEC at the FK station.

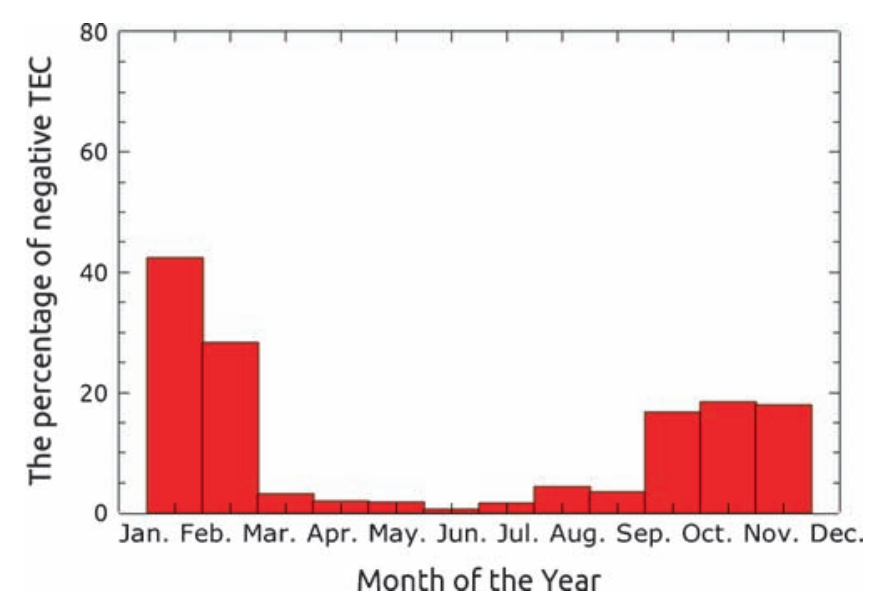

Figure 15. Percentage of negative TEC values (derived from GPS) in each month at the MH station.

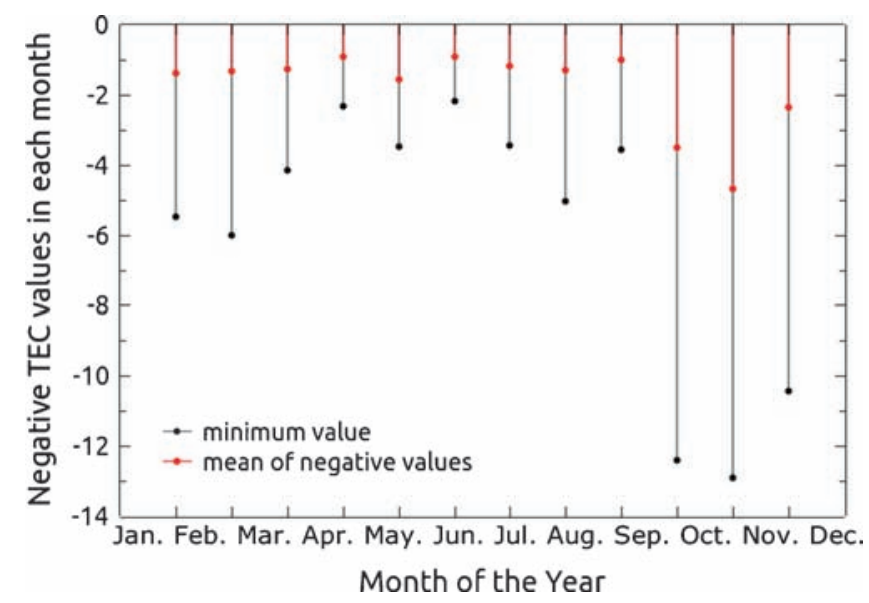

Figure 16. The minimum TEC value, monthly mean of the negative values in each month at $\mathrm{MH}$ station.

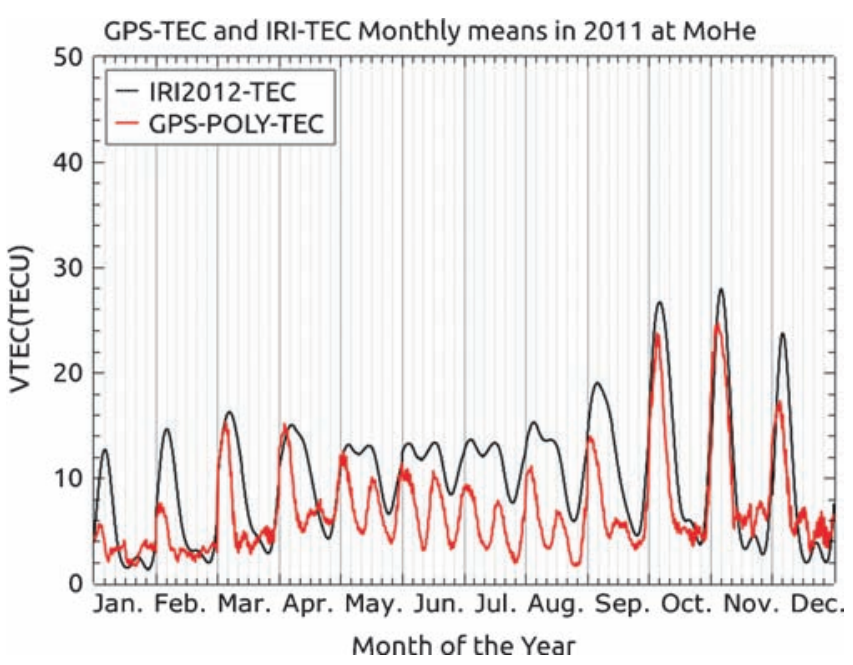

Figure 17. Comparison of refined GPS TEC and IRI-TEC at the MH station. 


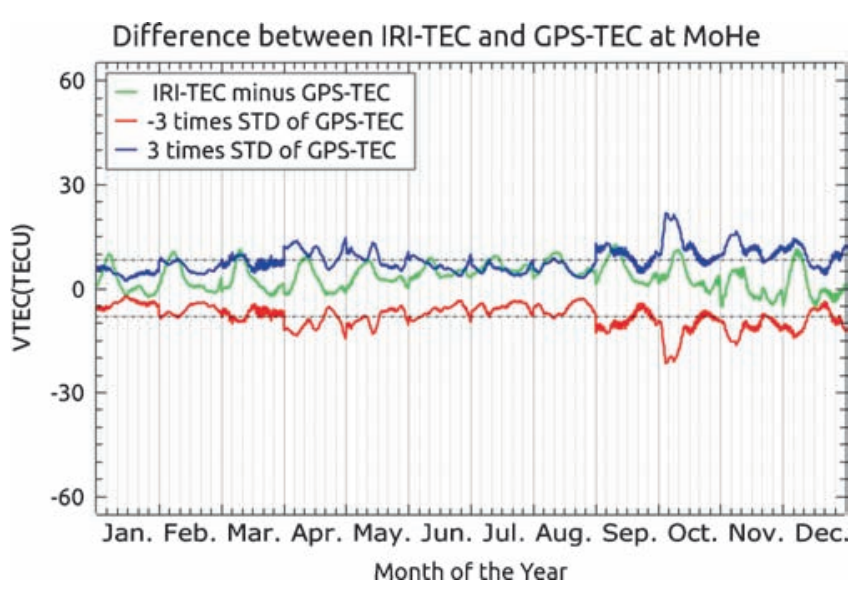

Figure 18. Difference between IRI-TEC and GPS-TEC at MH station.

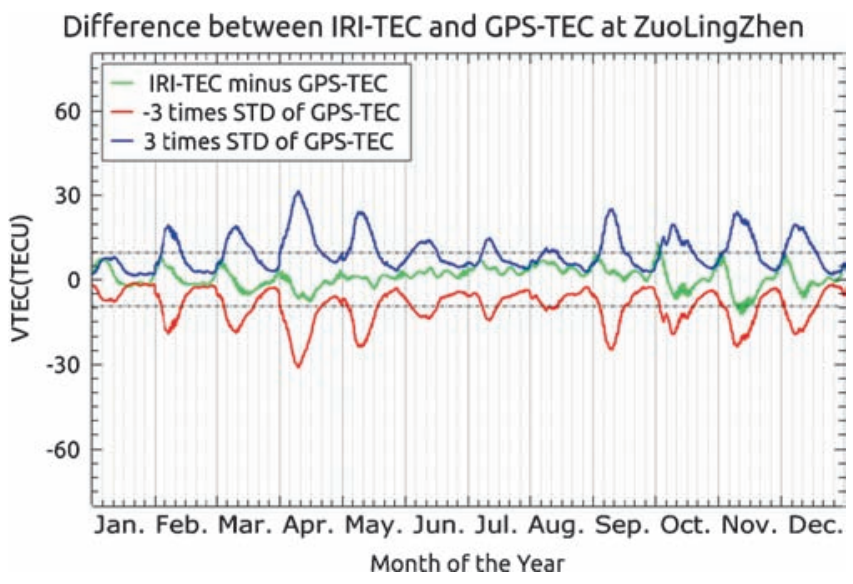

Figure 19. Difference between IRI-TEC and GPS-TEC at ZLZ station.

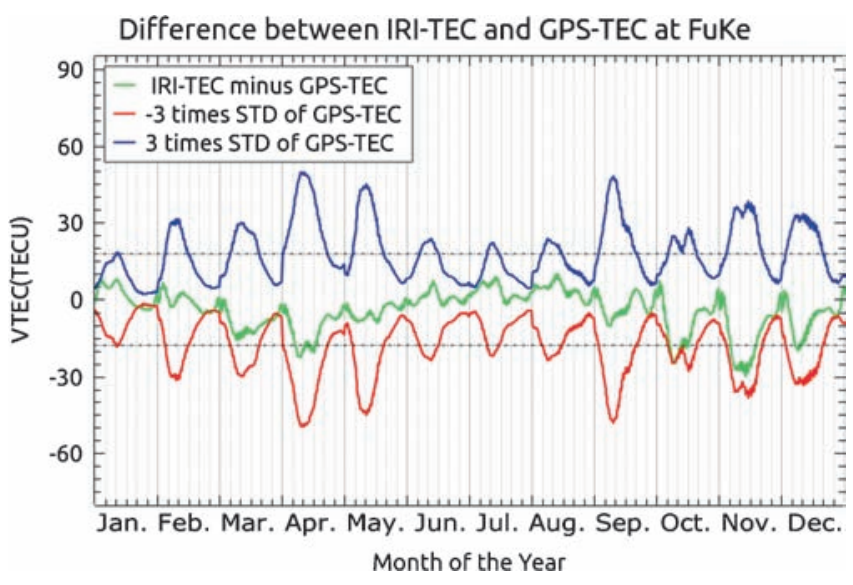

Figure 20. Difference between IRI-TEC and GPS-TEC at FK station.

observed TEC values and IRI2007 predictions in a declining phase of the solar cycle (2004-2006). The maximum difference of about 15 TECU during daytime was indicated. It is acceptable that the highest difference between observed TEC values at $\mathrm{FK}$ station and IRI model predictions is $~ 30$ TECU in an ascending phase of the solar cycle (2011). Bhuyan and Borah (2007) pointed out that TEC values are also significantly influenced by the strength of the equatorial electrojet (EEJ, an indicator of the electric field) which directly affects the ionization in the equatorial anomaly region. The changes of electric field would change the $\mathrm{E} \times \mathrm{B}$ drift. A number of researchers reported the positive correlation of $\mathrm{TEC} / \mathrm{NmF} 2$ and EEJ earlier (Rastogi et al. 1979; Sethia et al. 1980; Dabas et al. 1984; Bhuyan et al. 2003). Also, Nigussie et al. (2013) observed that the discrepancy between IRI model predictions and observed TEC values is mainly due to the errors associated to the slab thickness by the model. However, the differences between IRI-TEC and GPS-TEC are mostly within three standard deviations of GPS derived TEC values as shown in figures 18-20.

\section{Conclusion}

This paper presented a comparison of NmF2, hmF2, and TEC values obtained by GPS and ionosonde with an IRI model over China. It was tested by using indices of MD, RMSE, and RDMM. From the results of comparison between the observed values and the IRI model predictions, IRI2012 has higher precision of NmF2 and hmF2 values compared with IRI2007. However, it is possible to improve RDMM of NmF2, especially at low latitudes. The degree of agreement between GPS TEC and IRI-TEC in 2011 over China was investigated. The IRI2012 model overestimates TEC in the first half of autumn and winter and underestimates electron density in spring and the latter part of autumn. Additionally, TEC monthly means obtained by GPS and the IRI2012 model at the MH, ZLZ, and FK stations were compared. They have a good consistency at the ZLZ station. The IRI2012 model is not good at reproducing the variation of TEC values at the MH station. Meanwhile, IRI2012 underestimates TEC at the FK station in spring and winter. The highest difference between the observed GPS TEC and IRI2012 predicted TEC is $\sim 30$ TECU. This work is mainly about the validation of the IRI model over China. The precision of IRI2012 predicted TEC values over China is $\sim 5$ TECU. Nevertheless, two discontinuities in the IRI-TEC monthly means have been observed in November and December, which brought about bias in several TECU of TEC values between two adjacent months. The results and discussion of comparison in this work would be helpful to improve the IRI model in the future. 


\section{Acknowledgements}

The author acknowledges the use of data from the Chinese Meridian Project and CMONOC. He thank Dieter Bilitza and other researchers who contribute their effort on the IRI model. Additionally, thanks are due to $\mathrm{Yu}$ Jiao for the valuable discussion and revision. Also, the author would like to thank the anonymous reviewers and the editor for the comments and suggestions which are very helpful in revising the manuscript. This work is supported by the National Natural Science Foundation of China (No. 41274049) and National 863 Program of China (No. 2014AA123100).

\section{References}

Abdu M, Batista I and De Souza J 1996 An overview of IRIobservational data comparison in American (Brazilian) sector low latitude ionosphere; Adv. Space Res. 18(6) 13-22.

Adeniyi J, Bilitza D, Radicella S and Willoughby A 2003 Equatorial F2-peak parameters in the IRI model; Adv. Space Res. 31(3) 507-512.

Adewale A, Oyeyemi E, Adeniyi J, Adeloye A and Oladipo O 2011 Comparison of total electron content predicted using the IRI-2007 model with GPS observations over Lagos, Nigeria; Indian J. Radio Space Phys. 40(1) 21-25.

Araujo-Pradere E, Fuller-Rowell T and Bilitza D 2003 Validation of the STORM response in IRI2000; J. Geophys. Res.: Space Phys. 108 A3.

Bagiya M S, Joshi H, Iyer K, Aggarwal M, Ravindran S and Pathan B 2009 TEC variations during low solar activity period (2005-2007) near the equatorial ionospheric anomaly crest region in India; Ann. Geophys., Copernicus $\mathrm{GmbH}$.

Bertoni F, Sahai Y, Lima W, Fagundes P, Pillat V, BeckerGuedes F and Abalde J 2006 IRI-2001 model predictions compared with ionospheric data observed at Brazilian low latitude stations; Ann. Geophys. 24 2191-2200.

Bhuyan P and Borah R R 2007 TEC derived from GPS network in India and comparison with the IRI; $A d v$. Space Res. 39(5) 830-840.

Bhuyan P, Chamua M, Bhuyan K, Subrahmanyam P and Garg S 2003 Diurnal, seasonal and latitudinal variation of electron density in the topside F-region of the Indian zone ionosphere at solar minimum and comparison with the IRI; J. Atmos. Sol.-Terr. Phys. 65(3) 359-368.

Bilitza D 2001 International reference ionosphere 2000; Radio Sci. 36(2) 261-275.

Bilitza D, McKinnell L-A, Reinisch B and Fuller-Rowell T 2011 The international reference ionosphere today and in the future; J. Geodesy 85(12) 909-920.

Bilitza D, Obrou O, Adeniyi J and Oladipo O 2004 Variability of foF 2 in the equatorial ionosphere; Adv. Space Res. 34(9) 1901-1906.

Bilitza D and Reinisch B W 2008 International reference ionosphere 2007: Improvements and new parameters; $A d v$. Space Res. 42(4) 599-609.

Blewitt G 1990 An automatic editing algorithm for GPS data; Geophys. Res. Lett. 17(3) 199-202.

Brunini C, Meza A, Azpilicueta F, Van Zele M A, Gende M and Díaz A 2004 A new ionosphere monitoring technology based on GPS; Astrophys. Space Sci. 290(3-4) 415-429.
Coster A J, Gaposchkin E M and Thornton L E 1992 Real-time ionospheric monitoring system using GPS; Navigation 39(2) 191-204.

Dabas R, Bhuyan P, Tyagi T, Bhardwaj R and Lal J 1984 Day-to-day changes in ionospheric electron content at low latitudes; Radio Sci. 19(3) 749-756.

Dudeney J 1978 An improved model of the variation of electron concentration with height in the ionosphere; J. Atmos. Terr. Phys. 40(2) 195-203.

Dungey J 1955 The physics of the ionosphere; The Physical Society, London, 229p.

Haykin S 1994 Neural networks - a comprehensive foundation; Macmillan Publishing Company, Englewood Cliffs, NJ.

Hernández-Pajares M, Juan J, Sanz J, Orus R, Garcia-Rigo A, Feltens J, Komjathy A, Schaer S and Krankowski A 2009 The IGS VTEC maps: A reliable source of ionospheric information since 1998; J. Geodesy 83(3-4) $263-275$.

Huang X Q and Reinisch B W 2001 Vertical electron content from ionograms in real time; Radio Sci. 36(2) 335-342.

Ikubanni S, Adeniyi J and Obrou O 2014 Monthly mean foF2 model for an African low-latitude station and comparison with IRI; Adv. Space Res. 53(4) 635-646.

Kenpankho P, Supnithi P and Nagatsuma T 2013 Comparison of observed TEC values with IRI-2007 TEC and IRI-2007 TEC with optional foF2 measurement predictions at an equatorial region, Chumphon, Thailand; $A d v$. Space Res. 52(10) 1820-1826.

Klobuchar J 1987 Ionospheric time-delay algorithm for single-frequency GPS users; IEEE Trans. Aerospace and Electronic Systems 3 325-331.

Lee C-C and Reinisch B W 2006 Quiet-condition hmF2, $\mathrm{NmF} 2$, and $\mathrm{B} 0$ variations at Jicamarca and comparison with IRI-2001 during solar maximum; J. Atmos. Sol.-Terr. Phys. 68(18) 2138-2146.

Lei J, Liu L, Wan W and Zhang S R 2005 Variations of electron density based on long-term incoherent scatter radar and ionosonde measurements over Millstone Hill; Radio Sci. 40(2).

Liu L, Wan W, Ning B and Zhang M L 2009 Climatology of the mean total electron content derived from GPS global ionospheric maps; J. Geophys. Res.: Space Phys. 114 A6.

Ma G and Maruyama T 2003 Derivation of TEC and estimation of instrumental biases from GEONET in Japan; Ann. Geophys. 21 2083-2093.

Makela J J, González S A, MacPherson B, Pi X, Kelley M C and Sultan P J 2000 Intercomparisons of total electron content measurements using the Arecibo incoherent scatter radar and GPS; Geophys. Res. Lett. 27(18) $2841-2844$.

Matteo N and Morton Y 2010 Higher-order ionospheric error at Arecibo, Millstone, and Jicamarca; Radio Sci. 45(6) 2739-2740.

McNamara L 1984 Prediction of total electron content using the International Reference Ionosphere; Adv. Space Res. 4(1) $25-50$.

Miyazaki S, Saito T, Sasaki M, Hatanaka Y and Iimura Y 1997 Expansion of GSI's nationwide GPS array; Bull. Geogr. Surv. Inst. 43 23-34.

Mosert M, Gende M, Brunini C, Ezquer R and Altadill D 2007 Comparisons of IRI TEC predictions with GPS and digisonde measurements at Ebro; Adv. Space Res. 39(5) 841-847.

Nigussie M, Radicella S, Damtie B, Nava B, Yizengaw E and Groves K 2013 Validation of the NeQuick 2 and IRI2007 models in East-African equatorial region; J. Atmos. Sol.-Terr. Phys. 102 26-33. 
Okoh D, McKinnell L-A, Cilliers P and Okeke P 2013 Using GPS-TEC data to calibrate VTEC computed with the IRI model over Nigeria; Adv. Space Res. 52(10) 17911797.

Olwendo O, Baki P, Cilliers P, Mito C and Doherty $\mathrm{P}$ 2013 Comparison of GPS TEC variations with IRI-2007 TEC prediction at equatorial latitudes during a low solar activity (2009-2011) phase over the Kenyan region; $A d v$. Space Res. 52(10) 1770-1779.

Oyeyemi E, Adewale A, Adeloye A and Olugbon B 2013 An evaluation of the IRI-2007 storm time model at low latitude stations; Adv. Space Res. 52(10) 17371747.

Oyeyemi E, Poole A and McKinnell L 2005 On the global model for foF2 using neural networks; Radio Sci. $40(6)$.
Rastogi R, Sethia G, Chandra H, Deshpande M, Davies K and Murthy B 1979 Total electron content and F-region electron density distribution near the magnetic equator in India; J. Atmos. Terr. Phys. 41(6) 561-564.

Sethia G, Rastogi R, Deshpande M and Chandra H 1980 Equatorial electrojet control of the low latitude ionosphere; J. Geomag. Geoelectr. 32(4) 207-216.

Sobral J, Abdu M, Muralikrishna P, LaBelle J, Castilho V M and Zamlutti C 2003 Rocket and ground-based electron density soundings versus IRI representation; Adv. Space Res. 31(3) 569-575.

Wichaipanich N, Supnithi P, Tsugawa T, Maruyama T and Nagatsuma T 2013 Comparison of ionosphere characteristic parameters obtained by ionosonde with IRI-2007 model over southeast Asia; Adv. Space Res. 52(10) 1748-1755.

MS received 14 October 2015; revised 21 December 2015; accepted 24 January 2016

Corresponding editor: K KRISHNAMOORTHY 